\title{
ASPECTOS RADIOGRÁFICOS E ULTRA-SONOGRÁFICOS DOS PACIENTES SUBMETIDOS A ALONGAMENTO ÓSSEO PELO MÉTODO DE ILIZAROV*
}

\author{
Patrícia Martins e Souza ${ }^{1}$, Edson Marchiori ${ }^{2}$, Vanessa A. Dinoá $^{3}$, Irocy G. Knackfuss ${ }^{4}$
}

\begin{abstract}
Resumo Neste trabalho foram monitorados, por meio de radiografias simples e ultra-sonografias, dez pacientes submetidos a alongamento ósseo com o uso do fixador externo de llizarov, no período de março de 2001 a março de 2002. Os pacientes submetidos ao método de llizarov foram principalmente crianças e adolescentes, para correção de anomalias congênitas (seis casos). A correção do encurtamento se deveu a trauma complicado com osteomielite em três pacientes e a ressecção tumoral em um paciente. 0 fêmur esteve envolvido em $60 \%$ dos casos, a tíbia em $30 \%$ e a fíbula em $10 \%$. Os achados radiográficos encontrados na evolução normal do regenerado ósseo foram um centro radiotransparente, ossificação linear, reação periosteal, aumento das partes moles e ossificação completa. Os achados da formação do osso novo na ultrasonografia foram o regenerado anecóico, ecos esparsos no sítio de distração, ecos lineares alinhados longitudinalmente, ecos grosseiros e amorfos e calcificação completa. Ocorreram 15 complicações em seis pacientes: cisto no regenerado (cinco casos), infecção adjacente aos pinos (quatro casos), coleção em partes moles (três casos), consolidação precoce (dois casos) e retardo na consolidação (um caso).

Unitermos: llizarov; Alongamento ósseo; Radiografias; Ultra-sonografia.
\end{abstract}

Abstract Radiographic and sonographic findings in patients submitted to limb lengthening using the llizarov method. Ten patients treated with llizarov external fixator for limb lengthening were monitored with radiographs and sonography examinations between March, 2001 and March, 2002. Most of the patients were children and adolescents who were submitted to surgery for correction of congenital deformities (six cases). In three patients shortening was secondary to post-traumatic osteomielitis and in one patient due to tumor resection. The femur was affected in $60 \%$, tibia in $30 \%$ and fibula in $10 \%$ of the cases. The main radiographic findings of bone regeneration during the normal process of limb lengthening were lucent areas, linear ossification, periosteal reaction, soft tissue abnormalities and complete consolidation. Sonographic findings of new bone formation included anechoic areas, sparse echogenic foci within the distraction site, linear longitudinally oriented echogenic foci, amorphous and coarse echogenic foci and complete calcification. There were 15 complications in six patients: fluid collection at the distraction site (five cases), pin site infection (four cases), soft tissue collection (three cases), premature consolidation (two cases) and delayed consolidation (one case).

Key words: llizarov; Limb lengthening; Radiography; Sonography.

\section{INTRODUÇÃO}

O procedimento de Ilizarov é uma técnica criada e desenvolvida pelo ortopedista Gavriel Abramovich Ilizarov na década de cinqüenta, que revolucionou os princípios

* Trabalho realizado no Senviço de Radiodiagnóstico do Hospital Universitário Clementino Fraga Filho (HUCFF) da Universidade Federal do Rio de Janeiro (UFRJ), Rio de Janeiro, RJ.

1. Mestranda do Curso de Pós-Graduação em Radiologia da UFRJ.

2. Professor Titular da Universidade Federal Fluminense (UFF), Coordenador Adjunto do Curso de Pós-Graduação em Radiologia da UFRJ.

3. Professora Auxiliar de Radiologia da UFRJ.

4. Professor Adjunto de Ortopedia da UFRJ.

Endereço para correspondência: Prof. Dr. Edson Marchiori. Rua Thomaz Cameron, 438, Valparaíso. Petrópolis, RJ, 25685-120. E-mail: edmarchiori@zipmail.com.br.

Recebido para publicação em 20/11/2002. Aceito, após revisão, em 16/4/2003. de tratamento de diversas lesões ósseas ${ }^{(\mathbf{1 , 2})}$. Esta técnica utiliza-se de princípios matemáticos e de bioengenharia para, a partir da aplicação de forças tensionais aos tecidos com o uso de um fixador externo (aparelho que permite estabilizar a estrutura óssea por meio de pinos e fios de aço de aplicação percutânea), gerar a formação não apenas de tecido ósseo, mas também de tecidos de partes moles, incluindo músculos, nervos, vasos sanguíneos e pele, sem a utilização de enxertos ou transplantes ${ }^{(\mathbf{1 , 3})}$. Para isto, o osso é fraturado, sendo colocado o fixador externo e aplicadas forças tensionais através da "distração" — afastamento das duas partes ósseas (proximal e distal). Quando o objetivo é alcançado (alinhamento correto do osso e/ou o osso atingiu as dimensões pretendidas), a distração é interrompida, e após um período que varia de paciente para paciente, o fixador é retirado ${ }^{(3-6)}$.

Existem muitas indicações clínicas para a realização de cirurgias utilizando-se a técnica de Ilizarov: discrepância no tamanho dos membros, fraturas, pseudo-artroses, osteomielite crônica, deformidades congênitas e adquiridas e reconstrução de extremidades ${ }^{(\mathbf{1}, \mathbf{3}, \mathbf{5}, 7-\mathbf{1 2})}$.

A técnica de Ilizarov, também conhecida como "osteogênese de distração", vem ganhando cada vez mais popularidade e $\operatorname{adeptos}^{(\mathbf{4 , 1 3})}$, por ser um método relativamente pouco invasivo, realizado em apenas uma etapa, que acarreta sangramento mínimo, e ser extremamente versátil. Além 
disso, permite a formação de novos tecidos, que exibem as propriedades histológicas e mecânicas de um tecido normal; permite também a sustentação do peso durante o tratamento e pode ser utilizado em adultos e crianças, com o alongamento realizado em esquema ambulatorial ${ }^{(\mathbf{1 , 3}, 11,14-16)}$.

A despeito de todas essas vantagens, como em todo procedimento cirúrgico, o procedimento de Ilizarov não está livre de apresentar complicações ${ }^{(\mathbf{1 6}-19)}$. Os pacientes devem, portanto, ser cuidadosamente acompanhados e monitorados pelos métodos de imagem disponíveis, mais comumente a radiologia convencional e a ultrasonografia (US) ${ }^{(6,7,15,20)}$.

Por este motivo, é de crucial importância que o radiologista se familiarize com as várias técnicas disponíveis para o acompanhamento por imagem destes pacientes, sua aparência radiológica normal e as possíveis complicações ${ }^{(\mathbf{2 1})}$.

Neste trabalho foram analisados os aspectos radiológicos e ultra-sonográficos observados na evolução deste tipo de tratamento, e as principais complicações diagnosticadas por estes métodos de imagem.

\section{MATERIAIS E MÉTODOS}

Foram analisados, prospectivamente, dez pacientes submetidos a alongamento ósseo pela técnica de Ilizarov, no período de março de 2001 a março de 2002. As cirurgias foram realizadas no Serviço de Ortopedia do Hospital Universitário Clementino Fraga Filho (HUCFF) da Universidade Federal do Rio de Janeiro.

Foram analisados os aspectos epidemiológicos, relacionados à prevalência quanto ao sexo e idade dos 10 pacientes selecionados, bem como os motivos que os levaram a necessitar do procedimento proposto, e qual(is) o(s) osso(s) afetado(s).

O acompanhamento de rotina realizado pelo Serviço de Ortopedia é feito por meio de consultas ambulatoriais e radiografias simples (RX), agendadas para o dia da consulta, para que seja reduzido ao máximo o número de idas ao hospital, por motivos sócio-econômicos.

No dia da realização da consulta e do $\mathrm{RX}$, era também realizado exame ultra-sonográfico da área de interesse, em equipamento modelo Logic 400 (General Electric,
Milwaukee, USA), com transdutor linear multifreqüencial (7,5 a $11 \mathrm{MHz})$. A freqüência utilizada na maioria dos casos foi de $11 \mathrm{MHz}$, e freqüências menores $(8,2 \mathrm{e}$ $7,5 \mathrm{MHz}$ ) foram utilizadas nos casos com maior espessura das partes moles. Os pacientes foram avaliados pela primeira vez por volta da terceira semana do pós-operatório (variando da segunda à sexta semanas). As avaliações posteriores variaram entre semanais, quinzenais e mensais, dependendo das necessidades individuais.

Neste trabalho foram propostas duas classificações - uma radiográfica e outra ultra-sonográfica — dos achados no sítio do regenerado, de acordo com as suas características nas diferentes fases da ossificação, com o objetivo de correlacionar os achados de imagem com a evolução temporal da ossificação.

\section{a) Classificação em relação às radiografias}

Grau 1 - centro radiolucente; grau 2 redução da hipertransparência inicial, sem focos densos de ossificação; grau 3 - pequenos focos densos de ossificação; grau 4 - ossificação linear; grau 5 - calo ósseo bem formado, permitindo a retirada do fixador.

\section{b) Classificação em relação às US}

Grau 1 - ausência de ecos no sítio da distração; grau 2 - ecos esparsos; grau 3 ecos alinhados; grau 4 - ecos grosseiros, amorfos ou com maior ecogenicidade; grau 5 - ossificação completa com sombra acústica posterior.

Os casos foram fotografados, classificados em relação ao grau de ossificação e foram efetuadas medidas do regenerado por meio de régua milimetrada (radiografias) e dos cursores do aparelho de US. As medidas foram representadas em milímetros.

\section{RESULTADOS}

\section{a) Aspectos clínicos e epidemiológicos}

Dos dez pacientes estudados, seis eram do sexo masculino (60\%) e quatro, do sexo feminino (40\%). A idade variou de 4 a 61 anos, com média de 21,6 anos.

As indicações para o alongamento ósseo pelo método de Ilizarov nos pacientes selecionados foram divididas basicamente em causas congênitas, traumáticas e tumorais. A principal indicação foram as causas congênitas (60\% dos casos). Destas, as mais freqüentes foram displasia do quadril (dois casos), fêmur curto (dois casos), tíbia e fíbula curtas e epifisiólise (um caso cada). Nos casos de malformações congênitas, três pacientes já haviam sido submetidos a alongamento ósseo em outra ocasião, sendo o procedimento atual a segunda cirurgia corretiva.

Três casos tiveram causas traumáticas. Todos se deveram a trauma na tíbia complicado por osteomielite crônica, necessitando de seqüestrectomia, além do alongamento do membro afetado.

Um caso correspondeu a tumor de células gigantes do fêmur distal, localmente invasivo, necessitando de ampla ressecção cirúrgica para fins curativos. A técnica de Ilizarov foi uma tentativa de ressecção do tumor com a preservação do membro.

Em todos os casos estudados a técnica de Ilizarov foi utilizada em ossos longos dos membros inferiores. $\mathrm{O}$ fêmur foi o osso mais freqüentemente envolvido $(60 \%$ dos casos), seguido pela tíbia (30\% dos casos) e fíbula ( $10 \%$ dos casos).

\section{b) Complicações}

As complicações foram detectadas em seis pacientes (60\% dos casos), sendo as principais, em ordem decrescente de ocorrência: cisto no regenerado (cinco casos), infecção adjacente aos pinos (quatro casos), coleção em partes moles (três casos), consolidação precoce, impedindo o alongamento (dois casos), retardo na consolidação (um caso) e infecção da ferida operatória (um caso), totalizando 16 complicações em seis pacientes.

Imagem cística no interior do regenerado foi a complicação mais freqüente, observada em cinco dos seis pacientes que apresentaram complicações. Todos os casos foram detectados pela US e não tiveram expressão radiográfica (Figura 1 ). $\mathrm{O}$ tamanho dos cistos variou de 8,0 a 13,3 mm (diâmetro máximo), com média de 10,6 $\mathrm{mm}$. Os cistos tiveram resolução espontânea entre a quarta e décima semanas do pós-operatório. Foi adotada conduta conservadora em relação aos cistos.

A infecção adjacente aos pinos ocorreu em quatro pacientes, sendo caracterizada 


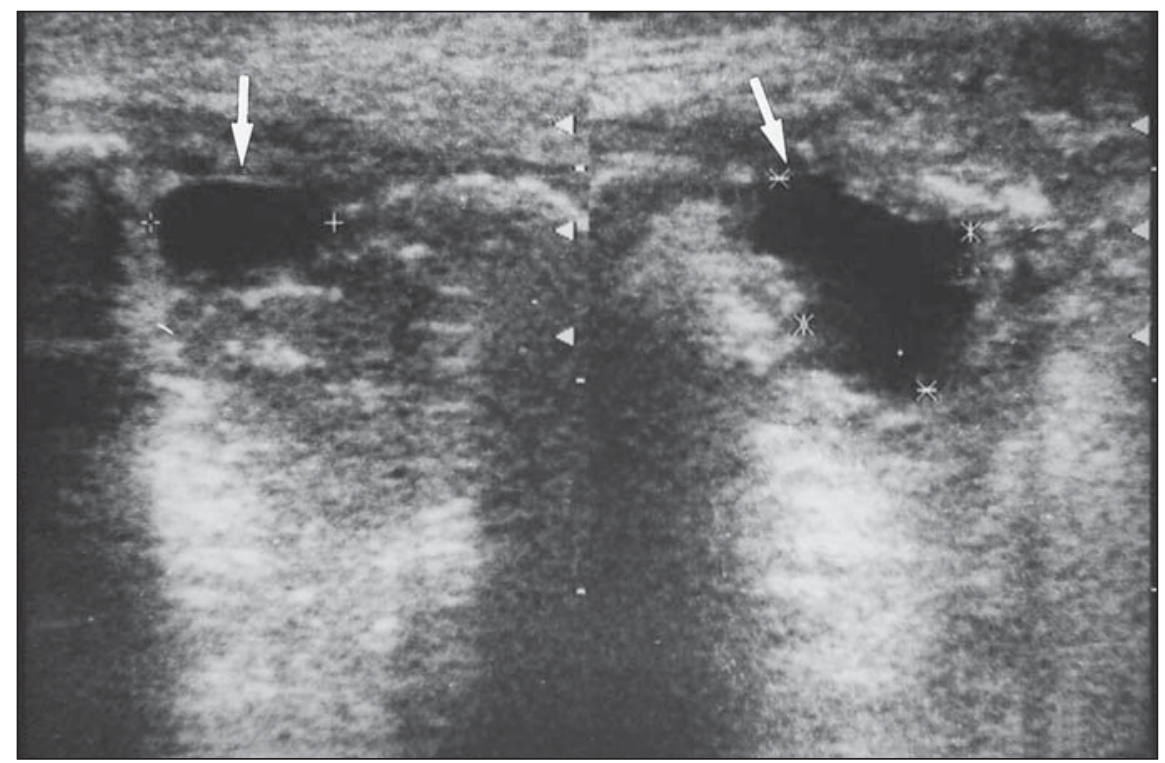

Figura 1. Ultra-sonografia revelando imagem cística (setas) no interior do regenerado.

pela saída de pequena quantidade de secreção purulenta adjacente à sua inserção. Todos os casos tiveram resolução espontânea, sendo adotada conduta expectante.

As coleções em partes moles ocorreram em três pacientes, sendo todas de pequeno volume. Elas tiveram resolução espontânea em no máximo nove semanas, e todas apresentavam associação com imagem cística no regenerado (Figura 2).

A consolidação precoce (formação de calo ósseo ao RX antes do término da distração) ocorreu em dois pacientes, ambos tendo que ser submetidos a nova cirurgia.

O retardo na consolidação, definido como ausência de formação de calo ósseo ao RX após seis meses da cirurgia, ocorreu em um paciente que sofreu fratura da tíbia complicada por osteomielite crônica por Staphylococcus aureus.

A infecção da ferida operatória ocorreu também neste paciente, que já apresentava ferida aberta antes da cirurgia, decorrente da osteomielite crônica com formação de abscesso e fístula cutânea. No pós-operatório foi identificada saída de pequena quantidade de secreção purulenta na ferida operatória e adjacente a alguns pinos. Estas infecções responderam bem a lavagens locais com água e sabão.

O número de complicações por paciente, no período de estudo, variou de um a quatro, com uma média de 2,6 complicações por paciente.

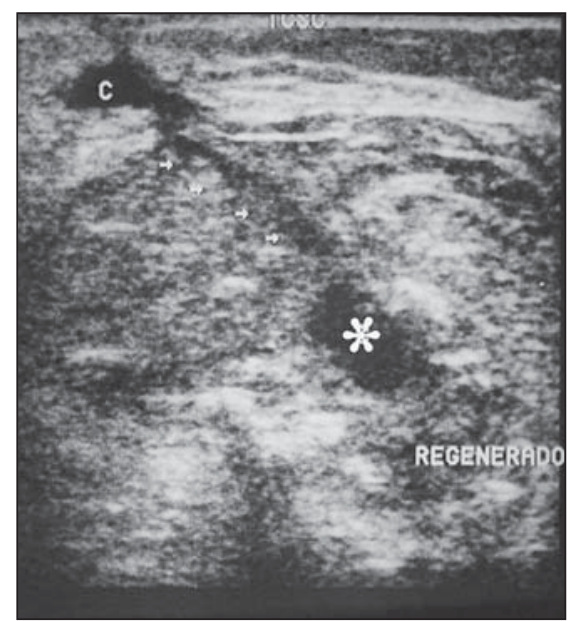

Figura 2. Identificação de comunicação entre a coleção em partes moles (c) e a imagem cística no interior do regenerado (asterisco). As setas mostram trajeto evidenciando comunicação entre as coleções.

Todos os pacientes chegaram ao final do alongamento, sendo o fixador retirado no período de 102 a 354 dias (média de 171,7 dias) do pós-operatório.

\section{c) Achados nas radiografias simples}

Todos os pacientes realizaram $\mathrm{RX}$ em posição ântero-posterior, nos mesmos dias da realização das US. Alguns pacientes fizeram complementos com radiografias em perfil e/ou oblíquas para melhor avaliação.

Os RX foram avaliados em relação a:

- Confirmação de que estava havendo alongamento ósseo de fato - Em dois pa- cientes as radiografias iniciais revelaram permanência da união entre as extremidades ósseas, indicando que não estava havendo alongamento do osso. Isto ocorreu devido a fratura incompleta do osso e a consolidação precoce.

- Em caso afirmativo, medida da distância entre as extremidades ósseas - A média do aumento do membro alongado foi de $5,7 \mathrm{~cm}$, variando de 3,5 a $11,0 \mathrm{~cm}$.

- Presença de reação periosteal no sítio da distração ou nas extremidades ósseas adjacentes - A reação periosteal foi identificada em quatro pacientes, a partir da segunda semana do pós-operatório (média de 4,5 semanas).

- Partes moles - Um paciente apresentava aumento significativo das partes moles, alteração que já existia antes da realização da cirurgia, sendo decorrente de osteomielite crônica.

- Formação de osso novo no sítio da distração - Em relação à formação do osso novo, foi utilizada a classificação estabelecida pelos autores em relação ao grau da ossificação do regenerado, descrita anteriormente.

Nas primeiras duas semanas de pósoperatório todos os pacientes foram classificados como grau 1. A partir da terceira semana, um paciente já apresentava grau 3 , e os restantes ainda permaneciam grau 1.

O grau 2 (pacientes cujo RX mostrava redução da hipertransparência inicial, porém não eram evidenciados ainda focos densos de ossificação) foi detectado em três pacientes: um na quarta semana, e que no exame seguinte, realizado na quinta semana, já era grau 4; outro na sexta semana, cujo exame subseqüente, realizado na décima semana, foi classificado como grau 3; e um paciente que foi classificado como grau 2 a partir da oitava semana, permanecendo nesta classificação até a $23^{\text {a }}$ semana, configurando retardo na ossificação.

O grau 3, detectado em quatro pacientes, foi identificado a partir da terceira, quinta e décima semanas, respectivamente. Todos estes pacientes ainda estavam em vigência do alongamento (Figura 3A).

O grau 4 foi identificado em cinco pacientes. O caso detectado mais precocemente foi na quarta semana do pós-operatório. O restante foi detectado da sexta até a $11^{\underline{a}}$ semanas, respectivamente. Destes 


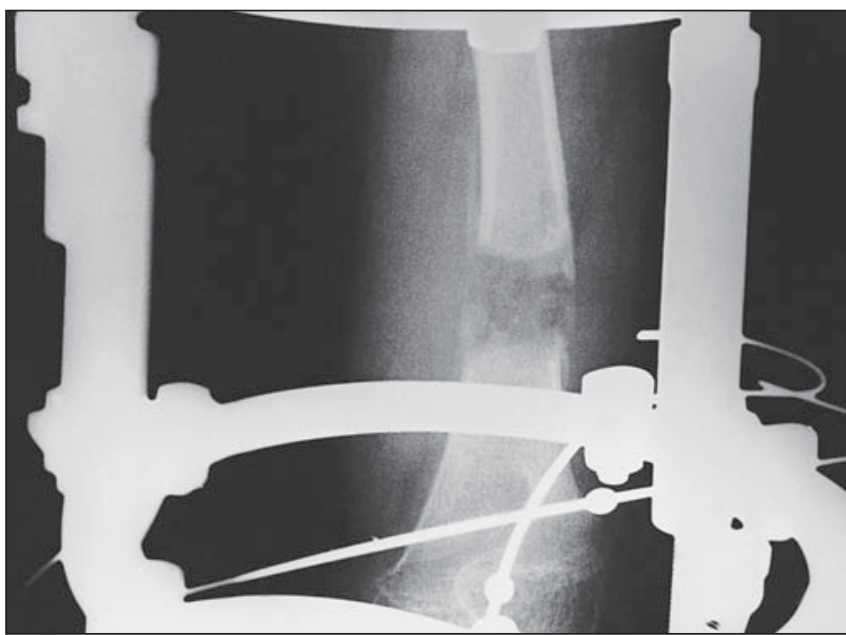

A

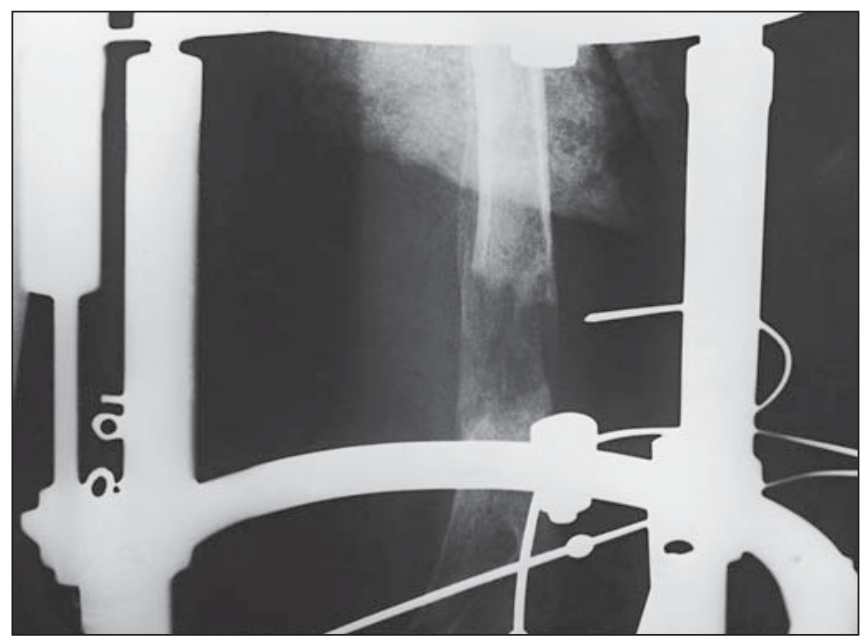

B

Figura 3. Em A, exame radiográfico obtido na terceira semana do pós-operatório, em que já são visíveis focos de ossificação no interior do regenerado. Notar também a reação periosteal na face látero-posterior do fêmur. Em $\mathbf{B}$, radiografia obtida após três semanas mostra que a ossificação assumiu a forma linear, direcionada no eixo longitudinal do osso.

cinco pacientes, dois já haviam interrompido o alongamento (Figura 3B).

O grau 5 foi detectado em todos os casos na época em que o aparelho foi retirado, sendo que em dois pacientes foi detectado após 12 e 14 semanas de pós-operatório, respectivamente. Ambos os pacientes apresentaram como complicação inicial a ossificação precoce, necessitando de nova intervenção cirúrgica. Além disso, um destes casos foi o que apresentou o grau 3 mais precocemente (na terceira semana de pós-operatório) (Figura 4).

\section{d) Achados na US}

Os parâmetros avaliados com a US foram os seguintes:

- Distância entre as corticais ósseas Até $3 \mathrm{~cm}$ foi observada boa correlação entre as medidas obtidas com o RX e a US. Acima de $3 \mathrm{~cm}$, as medidas obtidas com a US foram cerca de $2 \mathrm{~cm}$ menores do que as obtidas com o RX. Além disso, houve dificuldades técnicas para medições maiores que 4 a $5 \mathrm{~cm}$. Não foi possível avaliar adequadamente as medidas de um dos pacientes, cujo plano de fratura não foi transversal, e sim oblíquo.

- Ritmo da formação do osso novo - Foi também usada a classificação proposta pelos autores para avaliar o grau de ossificação com a US.

O grau 1 foi identificado apenas no paciente avaliado inicialmente na segunda semana do pós-operatório (Figura 5). Os
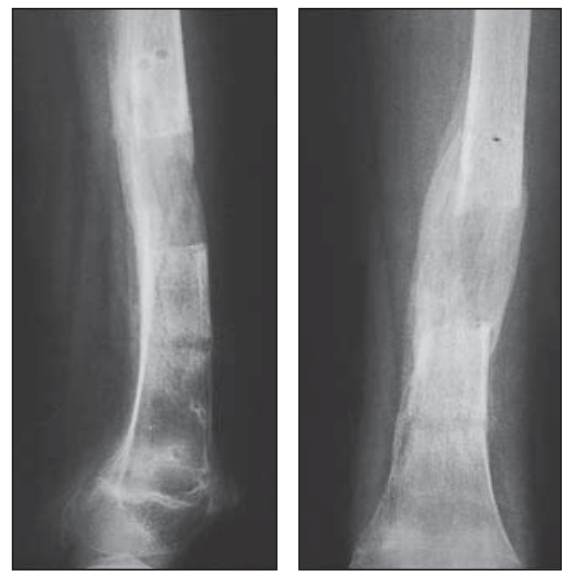

Figura 4. Radiografia obtida uma semana após a retirada do fixador mostrando o calo ósseo.

pacientes restantes, cuja avaliação inicial foi a partir da terceira semana de pós-operatório, foram caracterizados inicialmente como graus 2 ou 3 (Figuras 6A e 6B).

O grau 3 foi identificado em todos os pacientes, sendo que em três pacientes isto ocorreu a partir da terceira semana. Nos demais, o grau 3 foi identificado inicialmente desde a quinta até a oitava semanas do pós-operatório (média de 5,7 semanas).

O grau 4 só foi identificado a partir da nona semana do pós-operatório, e em apenas três pacientes que já haviam parado o alongamento (Figura 6C).

O grau 5 foi identificado em todos os pacientes, uma semana após a retirada do fixador externo (Figura 7).

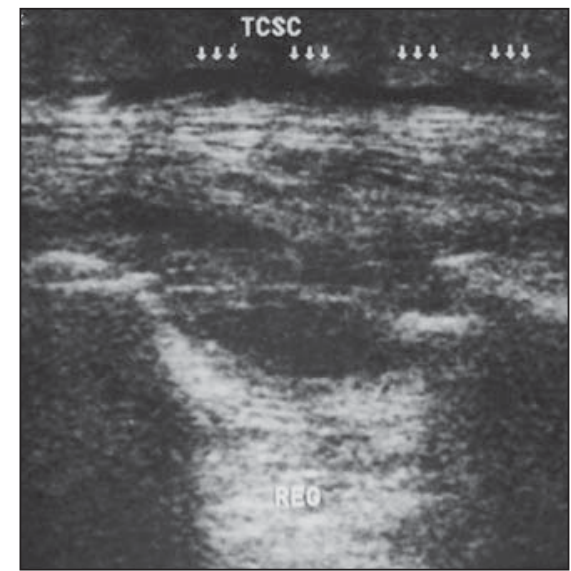

Figura 5. Exame ultra-sonográfico, em que praticamente não se evidenciam ecos no regenerado. Notar infiltração líquida no tecido celular subcutâneo.

- Sinais de calcificação periosteal - A calcificação periosteal foi identificada em todos os pacientes (Figura 8). Em um caso ela foi detectada já a partir da segunda semana do pós-operatório. Após a oitava semana, todos, à exceção de um caso, já demonstravam sinais ultra-sonográficos de ossificação do periósteo. Este paciente só foi apresentar sinais de calcificação periosteal a partir da $12^{\underline{a}}$ semana. A média de aparecimento da calcificação periosteal foi de 4,4 semanas.

- Identificação de cistos no interior do regenerado - Foram identificados cistos no regenerado em cinco pacientes. Em todos os casos a identificação ocorreu já no primeiro exame. O maior diâmetro variou de 


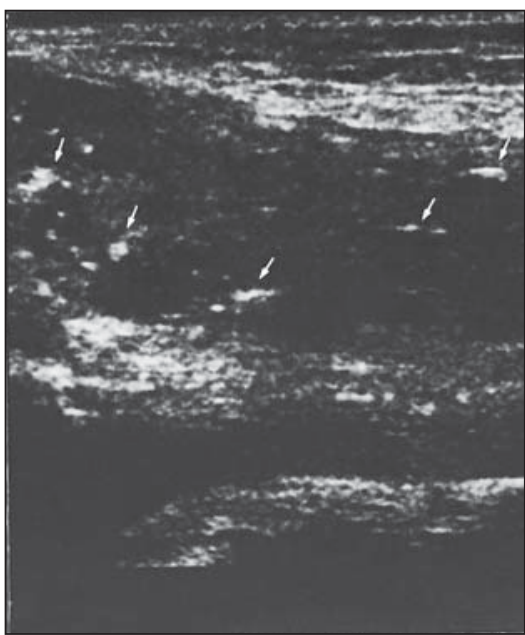

A

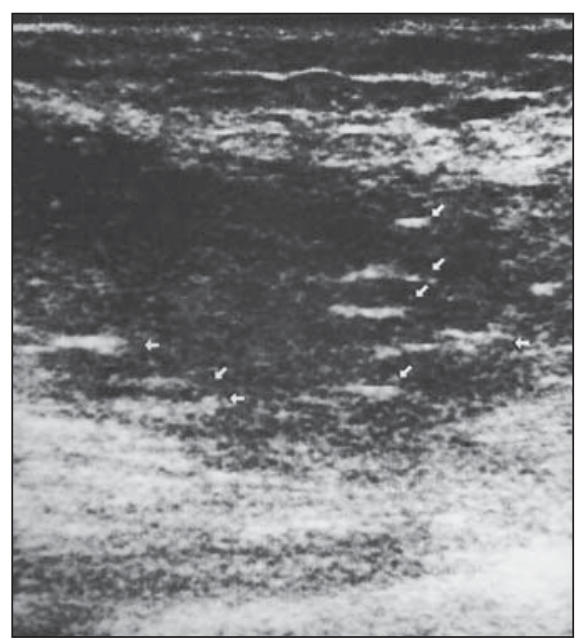

B

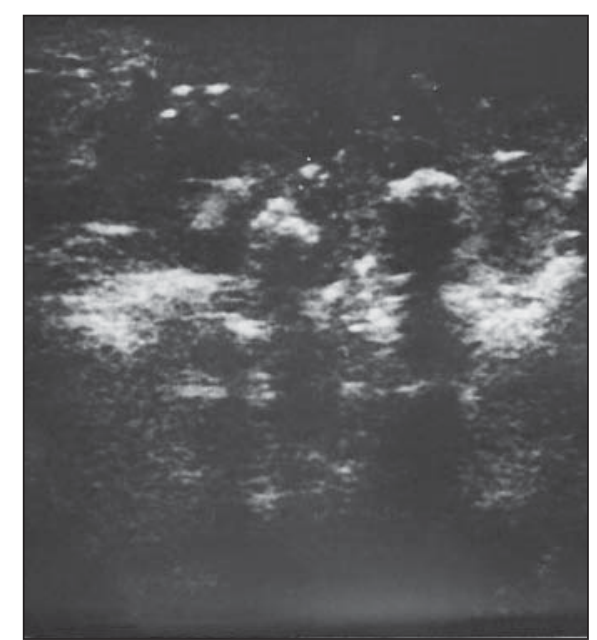

C

Figura 6. Em A, focos ecogênicos (setas) esparsos no regenerado (grau 2) observados na terceira semana do pós-operatório. Em B, os focos ecogênicos esparsos evoluíram para ecos alinhados no maior eixo longitudinal do osso (setas) na quinta semana do pós-operatório (grau 3). Em C, ecos amorfos, grosseiros, identificados na 18aㅗ semana de pós-operatório (grau 4).

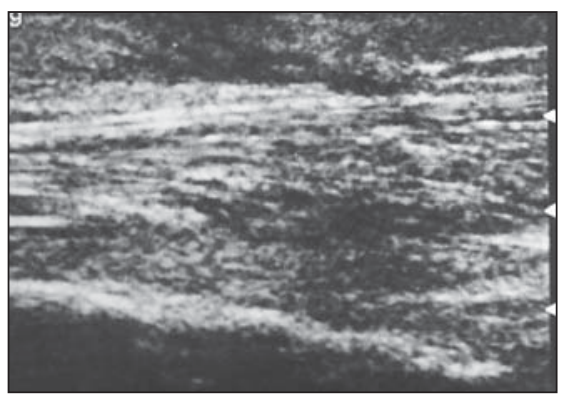

Figura 7. Ultra-sonografia mostrando sombra acústica posterior no calo ósseo totalmente formado.

8,3 a 13,3 mm (média de 10,3 mm). Todos os cistos, à US, regrediram espontaneamente até a décima semana do pós-operatório (média de 6,5 semanas).

- Avaliação das partes moles - Infiltração do tecido celular subcutâneo esteve presente por tempo variável em cinco pacientes. Um caso manteve a infiltração até depois da retirada do aparelho. Coleção em partes moles esteve presente em três, sendo que todos estes casos estavam associados à presença de cisto no regenerado. As coleções foram sempre de pequeno volume (menores que $5 \mathrm{ml}$, aproximadamente) e estiveram presentes até no máximo a nona semana de pós-operatório (média de cinco semanas). Em dois casos foi possível demonstrar a contigüidade entre o cisto no interior do regenerado e a coleção em partes moles (Figura 2).

- Avaliação do fluxo sanguíneo ao Doppler colorido - Apesar de não estar entre

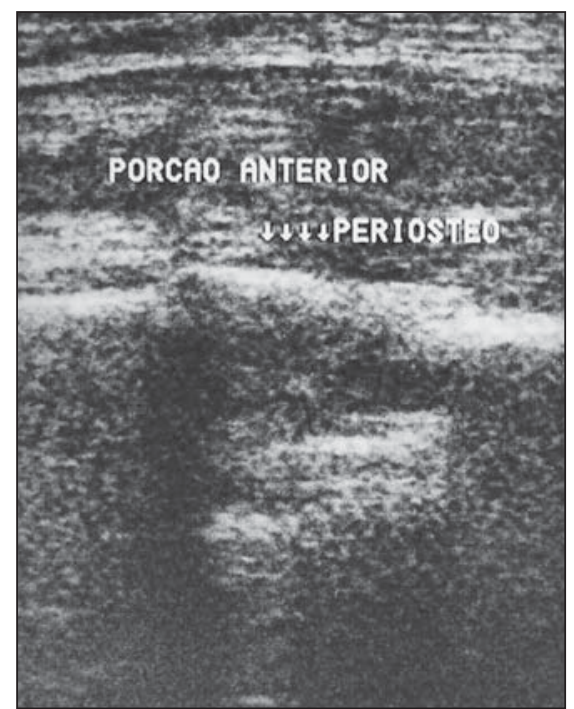

Figura 8. Ultra-sonografia demonstrando ossificação do periósteo (setas).

os objetivos deste trabalho a avaliação com o Doppler colorido, na maioria dos pacientes foi possível identificar vasos na periferia do regenerado, no interior do regenerado e adquirir curvas arteriais utilizando o Doppler pulsado.

\section{DISCUSSÃO}

O método de Ilizarov pode ser considerado uma revolução na cirurgia ortopédica. Além de poder ser utilizado em várias situações, como deformidades congênitas e adquiridas, fraturas, pseudo-artroses e osteomielite crônica, é, entre os métodos disponíveis para a realização de alongamento ósseo, o que mais oferece vantagens ${ }^{(\mathbf{1 , 3 , 5 , 7 - 1 2})}$. Dessa forma, o método vem ganhando cada vez mais popularidade e adeptos, sendo amplamente utilizado nos grandes centros ortopédicos de todo o mundo ${ }^{(\mathbf{4}, 18)}$. No HUCFF, a técnica de Ilizarov é bastante utilizada, tanto para a realização de correções angulares quanto para o alongamento ósseo. Neste trabalho, foram selecionados apenas os pacientes submetidos a alongamento ósseo, com ou sem correção angular associada.

Em relação à prevalência dos pacientes submetidos à técnica de Ilizarov, foram selecionados dez pacientes, sem diferença significativa quanto ao sexo (seis homens e quatro mulheres). As idades variavam de 4 a 61 anos, com maior prevalência nas duas primeiras décadas de vida $(70 \%$ dos casos). Como a maioria dos estudos encontrados na literatura abrangia pequenas séries, geralmente enfocando a experiência pessoal do(s) autor(es), é difícil determinar qual a prevalência geral do procedimento de Ilizarov em relação a sexo, idade, indicação ou osso acometido. A prevalência varia com o perfil do hospital e do cirurgião, se geral ou pediátrico, e com a indicação do procedimento. Deformidades congênitas, por exemplo, são mais prevalentes na população infantil. No nosso trabalho, todos os casos de malformações congênitas foram encontrados nas duas primeiras décadas de vida. O osso envolvido 
também varia com a indicação do procedimento. Todos os nossos casos de trauma ocorreram na tíbia, fato compartilhado por Marsh et al. ${ }^{(\mathbf{1 0})}$, que em seu estudo retrospectivo de 56 pacientes consecutivos submetidos ao procedimento de Ilizarov devido a fraturas complicadas por não-união, má-união ou infecção encontraram predominância da tíbia (70\% dos casos). Deve ser enfatizado, entretanto, que os dados numéricos encontrados neste trabalho devem ser avaliados com cautela, pois tratase de uma série pequena, avaliada em um curto período de tempo, não estando entre os objetivos do trabalho nenhuma análise estatística aprofundada.

Como todo procedimento cirúrgico é passível de complicações e a resposta individual à formação de osso novo é variável, é necessário um cuidadoso acompanhamento pós-operatório. Existem várias complicações descritas na literatura, algumas menores, nas quais a conduta empregada é apenas expectante, e outras maiores, em que se faz necessária nova intervenção cirúrgica ${ }^{(1,5,6,8-10,14,15,17,19,20)}$. Paley ${ }^{(19)}$ divide as dificuldades encontradas com o uso do método de Ilizarov em problemas (dificuldades que não necessitam de tratamento cirúrgico), obstáculos (dificuldades que necessitam de intervenção cirúrgica) e complicações verdadeiras (lesões intraoperatórias e dificuldades durante o alongamento que não foram resolvidas antes do término do tratamento). Em sua série de 60 segmentos alongados ocorreram 35 problemas, 11 obstáculos e 28 complicações verdadeiras. Segundo esta classificação, neste nosso trabalho foram encontradas 16 "dificuldades", sendo 14 "problemas", resolvidos sem a necessidade de nova cirurgia (88\% das "dificuldades"), e dois "obstáculos" (consolidação precoce com necessidade de nova cirurgia). Estas questões conceituais não estão ainda bem estabelecidas e variam entre os autores, sendo que, em geral, qualquer dificuldade ou achado diferente do esperado em termos de normalidade é encarado como complicação. Entre elas destacam-se a ocorrência de infecção local (uma das complicações mais freqüentes) ${ }^{(\mathbf{1 5})}$ ou sistêmica (relatada apenas por Marsh et $a l .^{(\mathbf{1 0})}$ ), a formação precoce (também um evento freqüente) ${ }^{(\mathbf{1 4})} \mathrm{ou}$ retardada do calo ósseo ${ }^{(10,17,19)}$, as contra- $\operatorname{turas}^{(\mathbf{8 , 9 , 1 4 , 1 9 )}}$, as fraturas ${ }^{\mathbf{( 8 , 9 , 1 4})}$, as deformidades residuais ${ }^{(\mathbf{9 )}}$ e as lesões nervosas ${ }^{(\mathbf{1 4 , 1 9 )}}$.

Os aspectos radiográficos consistem inicialmente em uma área radiolucente no sítio da distração ${ }^{(\mathbf{3 , 4 , 8 , 2 1})}$, com posterior formação do calo ósseo. Segundo Craig et $a l .{ }^{(\mathbf{8})} \mathrm{e}$ Walker et $a l .{ }^{(4)}$, a neoformação óssea é detectada geralmente a partir de 28 dias após a corticotomia, como colunas ósseas que ficam progressivamente maiores e mais densas, à medida que ocorre o aumento da ossificação. Young et al. ${ }^{(\mathbf{5})}$ observaram o início da formação óssea nas radiografias a partir de dois a seis meses do pós-operatório em 12 pacientes. Em sua série, não foram observados sinais de ossificação ao RX em nenhum paciente antes de oito semanas. Eyres et al. ${ }^{(\mathbf{3})}$ observaram neoformação óssea ao RX a partir de quatro a oito semanas. Na literatura consultada, os achados nas radiografias são descritos apenas como "área radiolucente" e "formação progressiva do calo ósseo", não sendo encontrado nenhum critério de quantificação da formação óssea, com o uso das radiografias.

Os aspectos ultra-sonográficos do sítio da distração foram descritos como centro hipoecóico inicial, que evolui para a detecção de ecos no interior do regenerado a partir da segunda semana após o início da distração, que após cerca de quatro semanas progressivamente tornam-se alinhados em relação ao eixo longitudinal do osso, aumentando em número e tamanho, até coalescerem como um osso ecogênico, determinando forte sombra acústica poste-

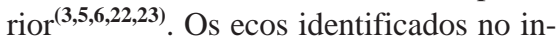
terior do regenerado representam a osteogênese, sendo detectados várias semanas antes das radiografias ${ }^{(\mathbf{5 , 1 3})}$.

Merece discussão à parte a ocorrência de cisto no interior do regenerado. Nos estudos de Malde et al. ${ }^{(\mathbf{1 7 )}}$ e Young et al. ${ }^{(\mathbf{5})}$, as formações císticas encontradas foram abordadas com aspiração, dando saída a material seroso ou sero-sanguinolento, respectivamente. A justificativa da aspiração foi a de evitar área de fraqueza no calo ósseo. A detecção do cisto, tanto no presente trabalho quanto na literatura, foi feita por meio da US em todos os casos, não tendo os cistos avaliados expressão nos RX. Na nossa casuística a ocorrência de cisto no regenerado foi a complicação mais fre- quiente (dos seis pacientes que apresentaram complicações, foram observados cistos no regenerado em cinco). Em todos estes pacientes foi adotada conduta expectante, visto que os cistos eram pequenos (menores que $15 \mathrm{~mm}$ ), sendo observada resolução espontânea entre a quarta e décima semanas de pós-operatório em todos os pacientes. Estes resultados podem levar à hipótese de os "cistos" menores de 15 mm não serem uma complicação verdadeira, e sim representarem fluido sero-sanguinolento residual pós-cirúrgico, sendo portanto um achado normal.

Young et al. ${ }^{(5)}$ encontraram cistos medindo, respectivamente, 1,5 e $2 \mathrm{~cm}$ de diâmetro, em dois dos 23 segmentos estudados. Eles foram abordados com aspiração, pois, segundo esses autores, isto eliminaria uma potencial fraqueza ou ossificação inadequada no sítio da distração, devido à perda de formação de osso novo no interior dos cistos. Craig et al. ${ }^{(\mathbf{8})}$ consideram que os cistos podem ser um indicador de que o ritmo da ossificação está lento em relação ao ritmo do alongamento. Em seu estudo, os seis cistos encontrados também foram aspirados, sendo que um deles apresentou recorrência. Não foram encontrados outros estudos que comprovem estas suposições ou que tenham acompanhado a evolução de cistos, limitando-se apenas a citar sua ocorrência e a vantagem da US na sua detecção ${ }^{(17)}$.

De qualquer forma, em virtude da possível ocorrência de complicações e do fato de que a neoformação óssea ocorre de maneira variável entre os pacientes, é imprescindível o acompanhamento destes pacientes com métodos de imagem. Isto é feito, de maneira geral, através de radiografias convencionais e, mais recentemente, em associação com a US ${ }^{(4,5,13,22)}$. Cada método tem suas peculiaridades e oferece determinadas vantagens.

A US tem sido cada vez mais utilizada por muitas razões. Em primeiro lugar, não usa radiação ionizante. Isto é de extrema importância nos pacientes que são submetidos ao método de Ilizarov, pois, em virtude da doença de base (na maioria dos casos traumas complicados ou anomalias congênitas), eles são submetidos a um número muito grande de radiografias ao longo da vida. Alguns autores ${ }^{(12,22)}$ afirmam 
que a US pode reduzir o número de radiografias, conseqüentemente reduzindo a exposição à radiação ionizante.

A US permite a detecção de neoformação óssea de quatro a sete semanas (podendo em alguns casos chegar a até 16 semanas) antes das radiografias ${ }^{(5,8,13,18)}$. Isto facilita a adoção de uma conduta personalizada em relação ao ritmo do alongamento. Em alguns casos, não há sinais radiográficos de neoformação óssea, mas há evidências sonográficas de ossificação, permitindo que o ortopedista tenha confiança em continuar com o alongamento no ritmo normal, evitando paradas desnecessárias que iriam apenas adiar a retirada do aparelho. Em um de nossos pacientes as radiografias obtidas em todo o acompanhamento foram inexpressivas, mas as US revelaram que a ossificação estava evoluindo em uma velocidade mais lenta, porém estava presente. Com isto, o alongamento não foi interrompido, sendo apenas realizado num ritmo menor, ajustado ao caso.

Outra vantagem da US é a sua grande sensibilidade para avaliar as partes moles, permitindo o acompanhamento de possíveis coleções/hematomas. Neste trabalho elas estiveram presentes em três pacientes. Cabe ressaltar que nas vezes em que foram detectadas coleções, sempre havia a presença de um cisto no regenerado. Em dois casos foi possível demonstrar a contigüidade entre o cisto e a coleção, reforçando a hipótese de que o cisto nada mais é que líquido pós-cirúrgico residual.

Alguns autores afirmam que a US fornece medidas fidedignas do tamanho do regenerado ${ }^{(\mathbf{8 , 2 2})}$. Richter et al. $^{(\mathbf{1 2 )}}$ consideram a US mais sensível que a radiografia, porém nós concordamos com Malde et $a l .^{(17)}$, que acham as radiografias mais acuradas. Até cerca de $3 \mathrm{~cm}$ houve um bom paralelo entre as medidas obtidas com o RX e a US, porém, a partir de $3 \mathrm{~cm}$, a US passou a demonstrar medidas menores que a real. Em uma ocasião, um paciente apresentou duas medidas iguais obtidas com a US em um intervalo de duas semanas, levantando a dúvida de o alongamento não estar sendo feito adequadamente. Ao se realizar o RX, verificou-se que o alongamento estava dentro do esperado. Dessa forma, apesar de a US poder reduzir o número de radiografias, o RX é fundamen- tal nas seguintes situações: avaliação da angulação do membro (fundamental nos casos de correção angular e impossível de ser avaliada com a US), medida final do tamanho do regenerado, e avaliação final para decidir se o fixador externo tem condições de ser removido.

A literatura enfatiza a época em que os achados radiográficos e ultra-sonográficos surgem, a partir de quando são observados os primeiros focos ecogênicos à US, quando os ecos tornam-se alinhados, quando surgem os primeiros sinais de ossificação ao RX, etc. ${ }^{(15,22)}$. Para esta avaliação é necessário que os exames sejam realizados a intervalos curtos, regulares, e iguais para todos os pacientes. Assim será possível flagrar o início de cada etapa da ossificação pelos diferentes métodos e realizar uma comparação entre os pacientes.

No protocolo de Hughes et al. ${ }^{(\mathbf{2 1})}$ é preconizada a realização de US semanais durante as oito primeiras semanas do pósoperatório. Em nosso meio, entretanto, é praticamente impossível estabelecer visitas tão freqüentes ao hospital, por causa da imensa dificuldade que os pacientes apresentam de locomoção, por motivos sócioeconômicos.

Como a literatura revisada refere-se a casos na Rússia ${ }^{(\mathbf{1})}$ (onde boa parte do seguimento pós-operatório é realizado em ambiente hospitalar, com o paciente internado) ou em países desenvolvidos, não há relatos no que diz respeito às dificuldades enfrentadas pelos pacientes no transporte para o hospital.

Assim, neste trabalho, o enfoque foi na avaliação individual dos pacientes com os métodos de imagem. Isto explica o fato de que alguns pacientes, em uma avaliação radiográfica ou ultra-sonográfica, receberam grau 1, e na subsequiente já estavam com grau 4, por exemplo. Não é possível afirmar que os graus 2 ou 3 não ocorreram, pois em virtude do intervalo de acompanhamento ter sido maior, eles podem apenas não ter sido documentados.

O Doppler colorido e o pulsado parecem ser métodos promissores na avaliação da formação do calo ósseo, segundo artigos recentes na literatura ${ }^{(\mathbf{2 0 , 2 2})}$. Existem evidências de que o índice de resistência (IR) é um parâmetro que pode ser utilizado para a identificação dos casos de consolidação alterada. Apesar de serem necessários novos estudos, e de não estar entre os objetivos deste trabalho a avaliação com Doppler, foi possível demonstrar algum tipo de fluxo em praticamente todos os pacientes, tanto na periferia quanto no interior do regenerado.

Com relação ao tempo de permanência do fixador, os pacientes apresentaram uma média de permanência com o aparelho de 171,1 dias. O tempo de permanência foi influenciado por vários fatores:

- Distância entre as extremidades ósseas - Quanto maior o tamanho do regenerado, a tendência será um maior tempo de permanência com o aparelho, pois a quantidade de osso novo a ser formada é maior. Um dos pacientes, que alongou $11 \mathrm{~cm}$, foi o que permaneceu maior tempo com o fixador (354 dias); outro, que alongou apenas $3 \mathrm{~cm}$, permaneceu também o menor tempo com o aparelho (102 dias).

- Idade do paciente - Os pacientes mais jovens permaneceram menos tempo com o aparelho, quando comparados com os pacientes mais velhos. Um paciente de quatro anos alongou $4,5 \mathrm{~cm}$, permanecendo 102 dias com o aparelho, enquanto outro de 33 anos alongou $5 \mathrm{~cm}$, com tempo de permanência de 207 dias. Deve-se também levar em conta o tamanho do regenerado em relação ao tamanho total do osso envolvido. Alongar $5 \mathrm{~cm}$ em um fêmur de 10 $\mathrm{cm}$ significa um aumento de cerca de $33 \%$ no tamanho do osso, o que acarreta maior dificuldade do que o alongamento de $5 \mathrm{~cm}$ em um fêmur de $25 \mathrm{~cm}$, o que representa um aumento de $16 \%$ no tamanho do osso. $\mathrm{O}$ paciente que permaneceu mais tempo com o aparelho (345 dias) era também o paciente mais idoso (61 anos).

- Fumo - É descrito, na literatura, o papel do fumo em relação a atraso na ossificação e maturação óssea ${ }^{(\mathbf{1 2})}$. O paciente que apresentou maior tempo de permanência com o aparelho era fumante.

- Complexidade do caso - Casos mais complexos, que necessitavam de múltiplas correções ou que o estado do osso não era o ideal (como nos casos de osteomielite crônica), por exemplo, levavam os ortopedistas a indicarem um maior tempo de permanência com o aparelho, como medida preventiva para evitar fraturas após a retirada do fixador. 
Cabe ressaltar que o número total de pacientes é pequeno para uma análise comparativa fidedigna em relação ao tempo de permanência versus a idade ou o tamanho do regenerado, além da influência do tabagismo, não estando estas análises entre os objetivos deste trabalho.

Apesar de o acompanhamento ter sido variável entre os pacientes, muitas vezes a intervalos relativamente grandes, de forma alguma isto invalidou o trabalho, que avaliou os aspectos de imagem apresentados pelos pacientes, e com base nestes achados permitiu que o acompanhamento fosse determinado com bases individuais. Além disso, com base nos estudos de imagem, a conduta foi modificada em $45 \%$ dos pacientes: identificação de taxas de alongamento incorretas levaram a novas demonstrações de como o alongamento deve ser feito de maneira adequada; consolidação precoce detectada nos exames iniciais levou à realização de nova cirurgia; ossificação lenta levou a paradas e/ou reduções no ritmo do alongamento, enquanto a ossificação rápida levou à intensificação no ritmo do alongamento.

\section{REFERÊNCIAS}

1. Ilizarov GA. The principles of the Ilizarov method. Bull Hosp Jt Dis 1997;56:49-53.
2. Wolosker S, Knackfuss I, Marchiori E, Ikeda A, Rafful F, Faria MPC. Avaliação dos alongamentos ósseos segundo a técnica de Ilizarov através do estudo cintigráfico trifásico com 99m-Tc-MDP. Jornal do Aparelho Locomotor 1996;1:23-9.

3. Eyres KS, Bell MJ, Kanis JA. Methods of assessing new bone formation during limb lengthening. Ultrasonography, dual energy X-ray absorptiometry and radiography compared. J Bone Joint Surg Br 1993;75:358-64.

4. Walker CW, Aronson J, Kaplan PA, Molpus WM, Seibert JJ. Radiologic evaluation of limb-lengthening procedures. AJR 1991;156:353-8.

5. Young JWR, Kostrubiak IS, Resnik CS, Paley D. Sonographic evaluation of bone production at the distraction site in Ilizarov limb-lengthening procedures. AJR 1990;154:125-8.

6. Castello R. Osso. In: Sernik RA, Cerri GG, eds. Ultra-sonografia do sistema musculoesquelético. $1{ }^{a}$ ed. São Paulo, SP: Sarvier, 1999:229-33.

7. Bell DF, Boyer MI, Armstrong PF. The use of the Ilizarov technique in the correction of limb deformities associated with skeletal dysplasia. J Pediatr Orthop 1992;12:283-90.

8. Craig JG, Jacobson JA, Moed BR. Ultrasound of fracture and bone healing. Radiol Clin North Am 1999;37:737-51.

9. Huang SC. Leg lengthening by the Ilizarov technique for patients with sequelae of poliomyelitis. $\mathrm{J}$ Formos Med Assoc 1997;96:258-65.

10. Marsh DR, Shah S, Elliott J, Kurdy N. The Ilizarov method in nonunion, malunion and infection of fractures. J Bone Joint Surg Br 1997;79:273-9.

11. Rajacich N, Bell DF, Armstrong PF. Pediatric applications of the Ilizarov method. Clin Orthop 1992;(280):72-80.

12. Richter D, Hahn MP, Ostermann PA, Ekkernkamp A, Muhr G. Ultrasound follow-up of callus distraction: an alternative to roentgen diagnosis? Langenbecks
Arch Chir Suppl Kongressbd 1996;113:931-3.

13. Blane CE, Herzenberg JE, DiPietro MA. Radiographic imaging for Ilizarov limb lengthening in children. Pediatr Radiol 1991;21:117-20.

14. Atar D, Lehman WB, Grant AD, Strongwater A, Frankel V, Golyakhovsky V. Treatment of complex limb deformities in children with the Ilizarov technique. Orthopedics 1991;14:961-7.

15. Bassett GS, Morris JR. The use of the Ilizarov technique in the correction of lower extremity deformities in children. Orthopedics 1997;20:623-7.

16. Herbert AJ, Herzenberg JE, Paley D. A review for pediatricians on limb lengthening and the Ilizarov method. Curr Opin Pediatr 1995;7:98-105.

17. Malde HM, Hemmadi SS, Chadda D, Parihar ML, Bhosale PB, Kedar RP. The role of skeletal sonography in limb lengthening procedures. J Postgrad Med 1993;39:127-9.

18. van Holsbeeck MT, Introcaso JH. Sonography of the dermis, hypodermis, periosteum, and bone. In: van Holsbeeck MT, Introcaso JH, eds. Musculoskeletal ultrasound. Detroit: Mosby, 2001:348-50.

19. Paley D. Problems, obstacles and complications of limb lengthening by the Ilizarov technique. Clin Orthop 1990;(250):81-104.

20. Rizzato G, Abbona M, Mininel G. Bone and callus. In: Solbiati L, Rizzatto G, eds. Ultrasound of superficial structures. New York: Churchill Livingstone, 1995:377-82.

21. Hughes TH, Maffulli N, Green V, Fixsen JA. Imaging in bone lengthening. A review. Clin Orthop 1994;(308):50-3.

22. Caruso G, Lagalla R, Derchi L, Iovane A, Sanfilippo A. Monitoring of fracture calluses with color Doppler sonography. J Clin Ultrasound 2000;28:20-7.

23. Hughes TH, Maffulli N, Fixsen JA. Ultrasonographic appearance of regenerate bone in limb lengthening. J R Soc Med 1993;86:18-20. 